\title{
Editorial
}

\section{Normas de Publicação e a Qualidade da Produção Científica}

O estabelecimento de padrões de publicação é ação fundamental em qualquer área do conhecimento, pois permite padronizar a comunicação entre os cientistas e estabelece parâmetros de qualidade da produção acadêmica. Por estes motivos é que as normas de publicação são atualizadas periodicamente, de forma a atender as mudanças que um campo do conhecimento sofre em determinado período, além de possibilitar uma comunicação clara, considerando as necessidades impostas pelo desenvolvimento social e tecnológico. No presente número atualizamos as normas de publicação da Revista Psicologia: Teoria e Pesquisa adotando a sexta edição do manual de publicação da APA (APA, 2010).

Ainda que possa parecer estranho, principalmente para aquele que se inicia na tarefa de redação científica, um conjunto de padrões de publicação vai muito além de uma lista de regras de como se formatar um arquivo, inserir uma citação ou montar uma lista de referências. Padrões de publicação definem o que é aceito tanto no concernente a forma quanto a conteúdo. No caso específico dos padrões da APA, a normalização explicita uma epistemologia, com princípios de linguagem, estrutura de narrativa, alcance de conclusões, uso de citações, entre outras características peculiares à área (Madigan, Johnson, \& Linton, 1995). Uma tarefa fundamental, de qualquer contribuição a PTP, é que siga rigorosamente as normas, pois as mesmas são a base para a qualidade do conteúdo. De maneira geral, a forma de um manuscrito está diretamente relacionada à qualidade do seu conteúdo e, consequentemente, a sua relevância como contribuição para a psicologia.

A literatura sobre a normalização da APA é abundante. Além do próprio manual é possível encontrar vários outros textos, publicados em livros ou periódicos, que discutem o estilo APA de publicação. Entre estes destaco temas como a elaboração de relatos de pesquisa empírica (Bem, 2003), revisões de literatura (Bem, 1995) e da redação científica no padrão APA (Trzesniak \& Koller, 2009). Estas publicações discutem erros comuns na elaboração de manuscritos que seguem a normalização APA, como um tratamento ensaístico em uma revisão de literatura ou a descrição demasiadamente detalhada de estudos empíricos na revisão de um artigo. Em geral, o que se espera de uma revisão de literatura é que ela defina claramente um problema e toda a descrição feita seja econômica no sentido de dar subsídio para o problema central do texto, realizando uma avaliação explícita da literatura publicada. Já no caso do artigo empírico é esperado que os estudos revisados conduzam o leitor para a mesma linha argumentativa objeto do manuscrito, evitando descrições excessivas do método ou dos resultados e que não sejam relevantes para o argumento principal.
Vários são os elementos relativos à normalização da publicação em psicologia e não é função deste editorial esgotar a questão. Considera-se relevante chamar a atenção dos interessados em enviar contribuições para a Revista de que a normalização é muito mais do que uma lista de regras de formatação de arquivos, mas sim uma forma ampla de se compreender como deve ser conduzida a veiculação do conhecimento em psicologia. Estamos convictos de que os padrões de publicação garantem qualidade na veiculação de informações científicas, contribuindo para sua relevância e aumentado seu impacto. Por estes motivos definimos por adotar de forma integral o manual da APA, remetendo o leitor diretamente para este documento como guia para elaboração de manuscritos para PTP, simplificando as normas da Revista. Tomamos o cuidado de remeter o leitor para documento suplementar com diretrizes de adequação das normas da APA, no que se refere ao uso de expressões estatísticas e números, para redação em língua portuguesa. Os outros raros problemas de inconsistência entre as normas da APA e a redação em língua portuguesa serão resolvidos caso a caso.

Portanto, convidamos aos interessados em submeter contribuições que busquem seguir de forma atenta e cuidadosa os padrões de publicação da sexta edição do manual de publicação da APA antes de submeter seus manuscritos. Isto aumenta consideravelmente as chances de aceitação do seu trabalho.

\section{Ronaldo Pilati \\ Editor-Chefe}

\section{Referências}

APA. (2010). Publication manual of the American Psychological Association. Washington, DC: APA.

Bem, D. J. (1995). Writing a review article for Psychological Bulletin. Psychological Bulletin, 118(2), 172-177.

Bem, D. J. (2003). Writing the empirical journal article. In J. M. Darley, M. P. Zanna \& H. L. Roediger III (Eds.), The compleat academic: A practical guide for the beginning social scientist (pp. 171-204). Washington, DC: APA.

Madigan, R., Johnson, S., \& Linton, P. (1995). The language of psychology. American Psychologist, 50(6), 428-436.

Trzesniak, P., \& Koller, S. H. (2009). A redação científica apresentada por editores. In A. A. Z. P. Sabadini, M. I. C. Sampaio \& S. H. Koller (Eds.), Publicar em psicologia: Um enfoque para a revista cientifica (pp. 19-34). São Paulo: Casa do Psicólogo. 